\title{
Desain Interior Ramah Lansia
}

\author{
Suastiwi Triatmodjo \\ Fakultas Seni Rupa ISI Yogyakarta \\ suastiwi@isi.ac.id
}

\begin{abstract}
Abstrak
Sepuluh dua puluh tahun ke depan sebagian besar penduduk Indonesia adalah orang lanjut usia atau lansia, hasil sensus menunjukkan bahwa penduduk lansia pada tahun 2020 adalah 9,78 \%, diprakirakan tahun 2035 ada $15 \%$ dan menjadi $20 \%$ pada tahun 2045, oleh karenanya situasi di Indonesia dapat dikatakan menuju penuaan masyarakat. Dengan kecenderungan pertumbuhan penduduk seperti ini maka ilmu desain perlu menaruh perhatian yang lebih banyak terhadap masalah desain untuk para lansia dan mengantisipasinya dengan cara melakukan pengembangan baik dalam riset maupun penciptaan untuk memenuhi perubahan kebutuhan dan persyaratan desain bagi lansia tersebut. Seperti diketahui dengan bertambahnya usia maka kemampuan fisik manusia berubah, demikian juga dengan kemampuan panca indera, di samping hal itu kelompok lansia tersebut juga mengalami perubahan dalam pola hidupnya, seperti kehilangan pasangan dan hidup terpisah dari anak-anaknya. Kondisi-kondisi ini tentu akan melahirkan kebutuhan desain ruang dan peralatan hidup sehari-hari yang berbeda dengan masa sebelumnya. Sampai saat ini belum terlalu banyak riset maupun penciptaan desain interior yang berfokus pada lansia sebagai pemakainya. Riset awal yang berbasis pada pustaka ini berusaha untuk menjawab kebutuhan tersebut dengan membuat pemetaan terhadap bidang-bidang yang perlu dikaji dan dikembangkan maupun pendekatan riset maupun perancangan yang dapat diterapkan untuk menjalankannya. Harapannya ke depan riset dan perancangan desain interior untuk orang lanjut usia, khususnya di Indonesia, dapat lebih fokus, terarah, dan produktif.
\end{abstract}

Kata kunci: Desain ramah lansia, riset dan perancangan, universal design, user-centered design.

\begin{abstract}
In the next ten or twenty years, most of Indonesia's population will be elderly, the census result show that elderly population in the year 2020 is $9.78 \%$, it is predicted that in the year 2035 there will be $15 \%$ and $20 \%$ in the year 2045, therefore the situation in Indonesia can be said towards the aging society. With the trend of population growth like this, design science needs to pay more attention to design problems for the elderly and anticipate them by developing both research and development to meet these changing needs and requirements for the elderly. As it is known that with the increasing age, the physical abilities of humans change, as well as the ability of senses, in addition to that the elderly also experiences changes in their life style, such as losing their partner and living apart from their children. These conditions will certainly raise the need for new space design and daily living equipment that is different from the previous time. Until now there has not been too many research and development of interior designs that focus on the elderly. This initial library-based research seeks to answer this need by mapping out areas that need to be studied and developed as well as research and design approaches that can be applied to implement them. It is hoped that in the future research and development of interior design for the elderly shall be more focused, targeted, and productive.
\end{abstract}

Keywords: Elderly friendly design, research and design, universal design, user-centered design.

\section{Pendahuluan}

Pada tahun 2020 pemerintah Indonesia melalui Badan Pusat Statistik menyelenggarakan Sensus Penduduk, salah satu publikasinya adalah "Statistik Penduduk Lanjut Usia 2020". Peningkatan jumlah penduduk lanjut usia (selanjutnya disebut Lansia) menimbulkan konsekuensi yang kompleks, berbagai tantangan yang diakibatkan penuaan penduduk dapat mencakup hampir setiap 
aspek kehidupan. Pembacaan lanjut dari hasil sensus tersebut memberikan beberapa simpulan yang perlu menjadi perhatian dunia desain, salah satu simpulan penting adalah tentang besarnya jumlah penduduk lansia. Sepuluh dua puluh tahun ke depan sebagian besar penduduk Indonesia adalah orang Lansia, hasil sensus menunjukkan bahwa penduduk lansia pada tahun 2020 adalah $9,78 \%$ (dari $270=26,4$ juta jiwa), diproyeksikan tahun 2035 terdapat $15 \%$ (dari 305 $=45,75$ juta jiwa), dan menjadi $20 \%$ (dari $319=63,8$ juta jiwa) pada tahun 2045 , dalam situasi yang seperti ini Indonesia dapat dikatakan menuju penuaan masyarakat. Kecenderungan ini tidak hanya dialami oleh Indonesia tetapi juga banyak terjadi di negara yang memiliki jaminan kesehatan yang bagus sehingga harapan hidup masyarakatnya naik dan tinggi, di negara-negara maju situasi penuaan masyarakat sudah terjadi saat ini.

Kondisi ekonomi masyarakat Indonesia yang terus tumbuh disertai dengan jaminan kesehatan yang semakin baik, telah meningkatkan angka harapan hidup masyarakat. Ke depan angka ini akan naik terus, kalau melihat grafik penduduk yang dikeluarkan oleh Badan Pusat Statistik (selanjutnya BPS) maka terlihat bahwa pada tahun 2045 ada keseimbangan jumlah antara penduduk tua, muda (yang produktif) dan anak-anak. BPS menjelaskan pula bahwa dengan penambahan jumlah lansia diikuti dengan peningkatan rasio ketergantungan lansia terhadap penduduk produktif. Pada tahun 2020 , tercatat rasio ketergantungan lansia sebesar 15,54 yang artinya setiap 100 orang penduduk usia produktif (usia 15-59 tahun) harus menanggung 15 orang penduduk lansia. Para peneliti di BPS mengatakan bahwa bertambahnya jumlah lansia dari tahun ke tahun mengakibatkan banyaknya jumlah rumah tangga yang dihuni oleh lansia. Pada kurun waktu lima tahun terakhir, rumah tangga yang dihuni lansia tumbuh dari 25,75 persen menjadi 28,48 persen, dengan demikian dapat diartikan bahwa satu di antara empat rumah tangga di Indonesia merupakan rumah tangga lansia (Statistik Penduduk Lanjut Usia 2020) .

Dengan kecenderungan tumbuh seperti ini maka ilmu desain perlu menaruh perhatian yang lebih banyak terhadap masalah desain untuk lansia dan mengantisipasinya dengan cara melakukan pengembangan baik dalam riset maupun penciptaan untuk memenuhi kebutuhan hidup para lansia tersebut. Pemaknaan desain (interior) sebagai pemberi solusi dalam kehidupan manusia semestinya dapat dipraktikan, dalam hal ini membantu para Lansia beraktivitas dalam keseharian mereka, sehingga para Lansia dapat hidup secara lebih mandiri di tempat tinggalnya.

Seperti diketahui dengan bertambahnya usia maka kemampuan fisik manusia berubah, termasuk kemampuan panca indera, kognisi, serta emosinya. Di samping itu kelompok lansia tersebut juga mengalami perubahan dalam pola hidupnya, seperti kehilangan pasangan (suami atau istri), hidup terpisah dari anak-anaknya sehingga para Lansia seringkali harus hidup sendiri. Kondisi-kondisi ini tentu akan melahirkan kebutuhan desain ruang dan peralatan pendukung yang berbeda dengan masa sebelumnya, ketika mereka masih muda dan fisik masih sempurna dan kuat.

Sampai saat ini di Indonesia belum terlalu banyak riset maupun penciptaan desain interior yang berfokus pada lansia sebagai pemakainya. Dan tampaknya inisiatif perancangan interior yang berfokus kepada Lansia belum dapat diharapkan muncul dari sektor industri atau swasta, karena memang secara bisnis sektor tersebut belum menguntungkan. Oleh karena itu maka Perguruan Tinggi dan lembaga Pemerintah ataupun organisasi sosial non profitlah yang dapat diharapkan untuk mengambil peran aktif mempelopori pengembangan riset dan penciptaan area ini.

Artikel yang disampaikan ini merupakan hasil riset pustaka, sebuah upaya awal untuk menjawab kebutuhan tersebut dengan membuat pemetaan terhadap bidang-bidang yang perlu dikaji dan dikembangkan maupun pendekatan riset maupun perancangan yang dapat diterapkan untuk menjalankannya. Harapannya ke depan riset dan perancangan desain interior untuk orang lanjut usia, khususnya di Indonesia, dapat lebih fokus dan terarah. 


\section{Metode}

Riset yang berbasis pada pustaka ini berusaha untuk menjawab kebutuhan desain ruang dan peralatan pendukung yang yang sesuai dengan kondisi dan kemampuan fisik lansia. Tulisan ini juga dimaksudkan untuk melihat riset-riset baru yang sudah dilakukan terkait dengan desain dan desain untuk Lansia, dan dengannya diharapkan akan mengawali riset yang lebih dalam dan memicu peneliti dan pencipta muda yang aktif memberikan kontribusi di area ini.

\section{Pembahasan}

\section{Kelompok Lansia dan Perubahan fisik, kognisi dan emosi.}

Dalam pergaulan sehari-hari penampilan fisik seorang lansia dengan mudah dikenali, karena kelompok orang ini secara ketubuhan menampakan beberapa ciri fisik yang kelihatan, seperti keriput di kulit, rambut putih, punggung bungkuk dan gigi yang ompong. Semakin menua usia seseorang, tubuhnya mengalami berbagai perubahan, selain perubahan fisik seperti yang disebutkan tadi, lansia ternyata juga mengalami berbagai penurunan fungsi organ tubuh.

Dalam ilmu kesehatan orang tua (geriarti) disebutkan bahwa dengan bertambahnya usia seorang maka secara alami ada beberapa penurunan kemampuan tubuh fisiknya, ada 12 area yang berubah: 1) Fungsi jantung dan pembuluh darah, 2) Sistem pernapasan, 3) Sistem pencernaan, 4) Fungsi ginjal, 5) Tulang dan sendi, 6) Penglihatan, 7) Pendengaran, 8) Sistem kekebalan tubuh, 9) Sistem saraf, 10) Sistem hormon, 11) Penuaan kulit, dan 12) Penurunan tinggi badan (Flint \& Tadi, 2020). Tentu saja masing-masing orang akan mempunyai tingkat penurunan yang berbedabeda tempat dan intensitasnya.

Penuaan merupakan proses alami seiring bertambahnya usia seseorang, dengan demikian tidak ada pengobatan untuk menghentikan proses penuaan, namun begitu ada upaya-upaya yang bisa dilakukan agar para lansia tetap dapat menjalani hidup dengan sehat dan bahagia. Yaitu mengkonsumsi makanan sehat bergizi seimbang, berolahraga sesuai kemampuan, cukup istirahat, terawat secara medis, dan hidup di lingkungan yang 'ramah' Lansia.

Lansia pada masa sekarang kurang lebih masih dapat menggantungkan diri hidup dengan dibantu oleh anak-anaknya namun pada masa mendatang hal seperti ini mungkin tinggal kenangan. Dengan semakin kompleksnya kehidupan di masyarakat maka orang atau anak-anak mereka akan sibuk dengan urusan hidup mereka sendiri sehingga orang tua (lansia) akan lebih sulit untuk meminta bantuan kepada orang lain yang nota bene adalah anak atau saudaranya. Oleh karena itu kemampuan untuk tinggal di lingkungan hidup ramah Lansia adalah pilihan yang perlu dipersiapkan, yaitu rumah tinggal milik pribadi atau rumah tinggal bersama yang dapat memenuhi kebutuhan Lansia serta sesuai dengan kemampuan tubuh mereka yang sudah berubah.

\section{Kebutuhan baru}

Kebutuhan baru, terhadap desain yang dapat mengakomodasi penurunan kemampuan tubuh fisik, indra perasa, dan fungsi kognisi dijelaskan oleh Liu dan Lederer (Liu \& Lederer, 2009) sebagai berikut. Dalam hubungannya dengan desain untuk pendukung kehidupan sehari-hari maka perlu disadari bahwa fisik orang tua akan mengalami penurunan kemampuan pergerakan pada lansia juga berubah atau menurun, yaitu pada sisi kekuatan otot, kecepatan gerak dan fleksibilitas, postur \& keseimbangan serta daya penggerak. Dalam hal ini sudah banyak fasilitas yang memperhatikan kebutuhan tersebut yaitu penyediaan railing (pegangan tangan) pada dinding, pintu dorong, tempat duduk di kamar mandi, serta ukuran kamar mandi yang lebih longgar untuk para Lansia dengan kursi roda.

Selanjutnya masih ada hubungannya dengan aspek fisik adalah kemampuan persepsi yaitu pada aspek penglihatan, pendengaran, penciuman dan somatosensory. Kemampuan melihat adalah yang paling berpengaruh terhadap desain produk maupun lingkungan. Kemampuan mata mulai menurun 
dalam cakupan lapang pandang dan kepekaan terhadap kontras, kesilauan dan kemampuan membedakan warna. Desain yang biasanya disediakan adalah kontras yang jelas antar dinding dan lantai, kontras fasilitas kamar mandi dengan lingkungannya, menghindari motif lantai yang rumit dan ujung-ujung (furniture, dinding, dan lantai) yang tajam.

Ranah lain yang juga berubah adalah penurunan kognisi yaitu pada kemampuan memori, perhatian/ atensi dan kendali pelaksanaan/ executive kontrol. Para Lansia lebih sering kehilangan kemampuan mengingat dan lebih lambat dalam memahami sesuatu, oleh karena itu lingkungan perlu dirancang agar mudah diingat serta tidak rumit. Bila ada peralatan yang harus dioperasikan langkah-langkah operasinya sesedikit mungkin, bila perlu instruksi diberikan dengan suara dan gambar.

\section{Area dan pendekatan riset dan penciptaan desain interior}

Sejalan dengan bertambahnya usia maka pergerakan seorang manusia kemudian menjadi lebih terbatas, para lansia tidak lagi bekerja sehingga lebih banyak tinggal di rumah. Baik tinggal sendiri atau pun tinggal di rumah anak atau kerabatnya, atau tinggal di panti wreda. Lansia yang sehat sesungguhnya juga mampu melakukan perjalanan ke luar rumah bahkan pergi berwisata, tetapi dapat dipastikan dengan frekwensi yang sedikit dari pada orang yang masih muda.

Membaca pada referensi lama seperti Times Saver Standard for Building Types (Chiara, Panero, \& Zelnik, 1992), Ching (Ching, 1987), dan Design Interior (Kilmer \& Kilmer, 2014), tentang desain interior untuk Lansia maka secara umum dapat dikatakan bahwa ada tiga hal yang dibicarakan yaitu tentang ruang atau area, detil elemen dan perlengkapan ruang, serta persyaratan yang harus ada di dalam ruang tinggal tersebut. Menyimak pada referensi tersebut ternyata dalam kehidupan sehari-hari para Lansia hanya membutuhkan 5 area, dengan 6 detil elemen ruang yang perlu diberi perhatian secara khusus, dan 6 persyaratan yang harus dipenuhi. Secara garis besar kebutuhan para Lansia tersebut dapat ditunjukkan pada table berikut.

Tabel 1 Kebutuhan Lansia pada lingkungan tempat tinggalnya

\begin{tabular}{|l|l|l|l|}
\multicolumn{5}{|c|}{ (Sumber : Dokumen Pribadi, 2021 ) } \\
\hline 1. & Ruang atau area & \multicolumn{1}{c|}{$\begin{array}{c}\text { Detil elemen, perlengkapan } \\
\text { ruang }\end{array}$} & \multicolumn{1}{c|}{ Persyaratan } \\
\hline 2 & Ruang Duduk Santai & Lantai & $\begin{array}{l}\text { Aksesibilitas } \\
\text { diffabel fisik }\end{array}$ \\
\hline 3. & Kamang Tidur & Doors \& hardwares & Desain kompak \\
\hline 4. & Ruang Dapur & Pencahayaan & Keamanan dr kebakaran \\
\hline 5. & Ruang Makan & Penghawaan & Hemat pada perawatan \\
\hline 6. & Zona Jalur sirkulasi & Komunikasi dan sistem alaram & Keceriaan \\
\hline
\end{tabular}

Selanjutnya studi pada beberapa sumber lebih baru menunjukkan perkembangan yang semakin komplek dan dinamis terkait dengan fasilitas dan layanan untuk para lansia ini. Seperti yang ditemukan di Eropa dimana kehidupan Lansia sudah lebih terjamin dan mapan, maka untuk perancangan fasilitas dan layanannya telah didukung oleh kegiatan riset dan pengembangan yang maju pula. Riset dan pengembangan yang dikerjakan tidak terbatas pada produk tetapi sudah lebih luas mencakup pelayanan dan lingkungan hidupnya. Berikut disampaikan tiga contoh projek yang sedang dikembangkan di Eropa, untuk memberikan acuan baru, yaitu projek Ambient Assisted Live (AAL) (Costa, et al., 2008), Agile Co-creation for Robots and Aging (ACCRA), dan 'Bringing Care Home'.

AAL dapat didefinisikan sebagai pemakaian teknologi informasi dan komunikasi (ICT) pada lingkungan hidup dan kerja sehari-hari sehingga mereka dapat tetap aktif lebih lama, secara sosial tetap terhubung dan hidup mandiri di usia lanjut. Riset yang dikerjakan oleh komunitas AAL meliputi banyak topik, tetapi utamanya pada pengenalan aneka kegiatan manusia dan pemahaman 
terhadap perilaku, projek ini bertujuan untuk mendeteksi dan mengenali aksi, kegiatan, dan situasi di dalam suatu lingkungan hidup Lansia (Monekosso, Florez-Revuelta, \& Remagnino, 2015).

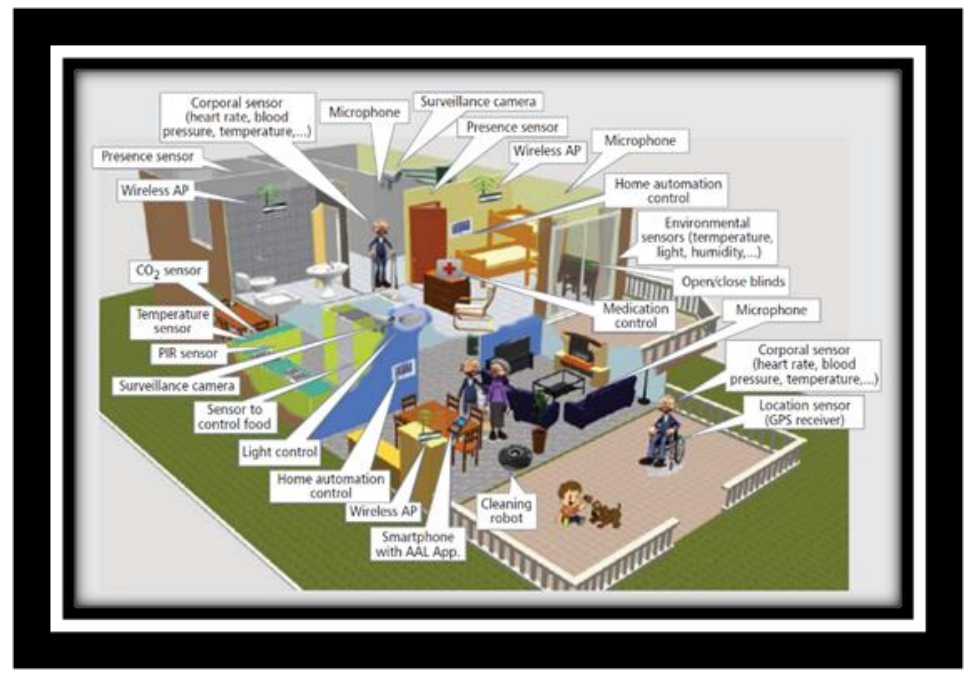

Gambar 1 A Smart communication Architecture dengan teknologi Ambient Assisted Live (AAL) Sumber : (bstassen wordpress.com, diakses 8 Juni 2021)

Projek lain yang berbasis ICT pula yaitu Agile Co-Creation for Robots and Aging (ACCRA), sebuah projek pemanfaatan teknologi baru bagi orang lanjut usia, pengembangan solusi berbasis robot dengan ICT terdepan, untuk memperpanjang kehidupan sehari-hari lansia secara aktif dan sehat. Program ini mirip dengan AAL tetapi lebih menekankan basisnya pada robot dan prosess pengembangnya yang co-creation.

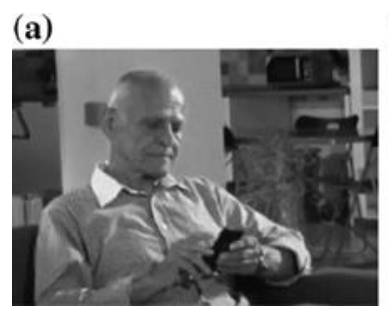

(b)

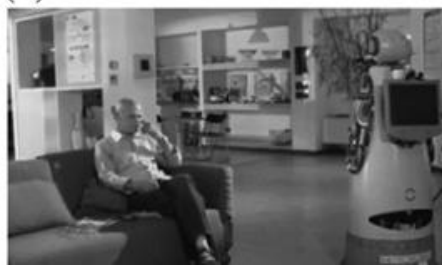

(c)

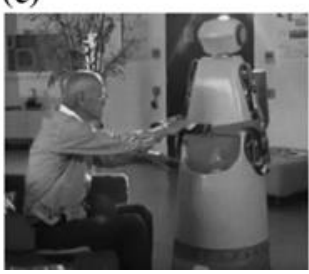

Gambar 2 Robot yang dikembangkan untuk melayani para Lansia Sumber : (Fiorini, et al., 2017)

Juga ada kompetisi proposal bisnis yang diprakarsai oleh The European Institute of Innovation \& Technology (EIT) Health, 'Bringing Care Home', yaitu merancang dan mendemonstrasikan sistem layanan kesehatan di rumah yang inovatif. Tujuan rencana bisnis tersebut adalah untuk menyediakan jasa perawatan kesehatan bagi para Lansia dengan basis (tinggal) di rumah, dengan syarat dapat memberikan keuntungan finasial kepada masyarakat (https://www.eithealth.eu//sparking-ideas-for-healthcare). 

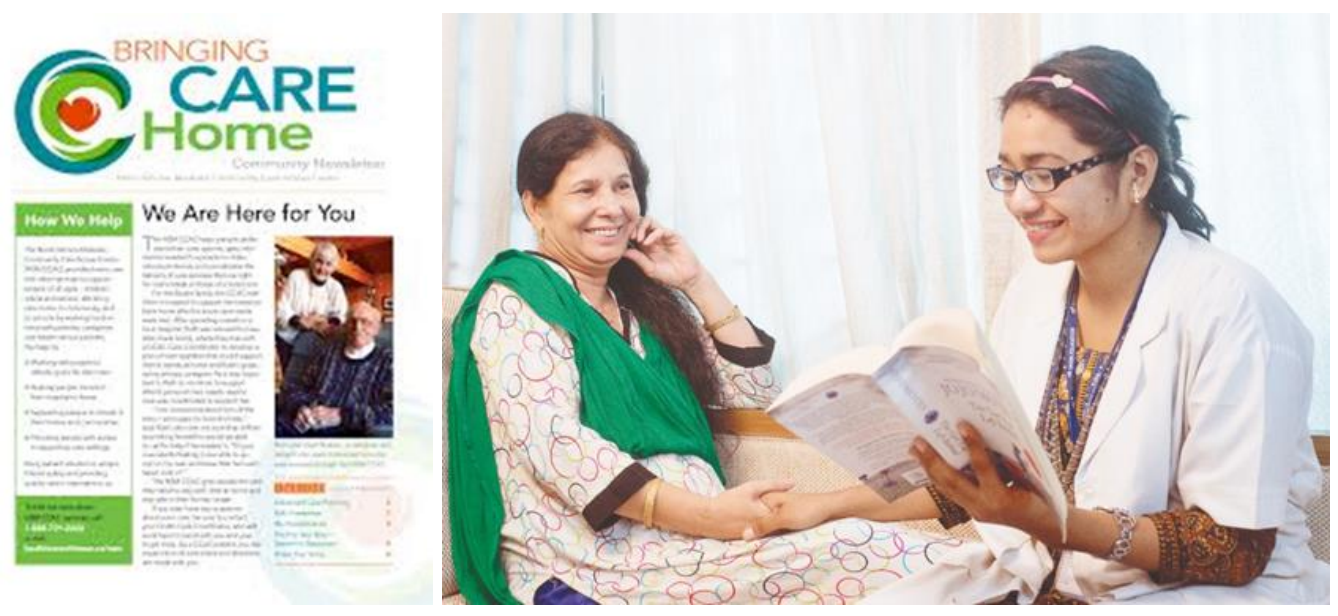

Gambar 3 Program Bringing Care Home smart Interior Sumber : (https://www.dhakatribune.com/feature/2019)

Disamping riset dan penciptaan untuk para Lansia ditujukan pada tempat tinggal baik milik sendiri maupun milik lembaga pemerintah maupun swasta, Eropa dan Negara maju yang lain sangat memperhatikan kebutuhan Lansia di tempat publik. Hal ini dapat dibaca lewat peraturan perundangan berikut: bahwa pelaku bisnis di tempat umum diminta untuk memberikan perhatian ekstra kepada para Lansia, sebagai contoh adalah di Scotlandia. Dengan peraturan Equality Act 2010, semua bisnis diwajibkan secara hukum untuk melakukan penyesuaian yang diperlukan bagi orang difabel (di negara ini Lansia termasuk golongan difabel). Ada beberapa pedoman ukuran dimana para pebisnis dapat menerapkannya agar lingkungan publik menjadi lebih inklusif.

- $\quad$ Pintu masuk cukup lebar agar kursi roda, skuter mobil, alat bantu jalan dapat masuk.

- Membersihkan sampah dari koridor dan gang

- Konter yang lebih rendah agar terjangkau

- Cetakan menu, leaflets, dan brosur dengan font huruf 14

- $\quad$ Signage yang jelas

- Visibilitas yang tinggi dengan kontras warna pada bahan untuk sudut, undakan dan lingiran (www.gov.scot/publications/fairer-scotland-older-people-framework-action )

Peraturan tersebut tampak sederhana tetapi bila hal ini konsisten dijalankan oleh masyarakat, pelaku bisnis dan pelaksanaannya diawasi oleh yang berwenang maka ini adalah sebentuk perhatian dan penghargaan kepada para Lansia dan para diffabel lainnya. Secara umum dapat dikatakan bahwa pengembangan desain untuk Lansia dalam dimensi ruang sebetulnya tidak berubah banyak yaitu masih disekitar rumah tinggal dengan 6 jenis ruang (lihat Tabel 1), serta di ruang publik, kamar mandi, jalur sirkulasi dan ruang duduk atau ruang makan di restaurant. Pada riset dan penciptaan masa kini perkembangan banyak terjadi pada pemakaian teknologi baru seperti AAL, robot, terkait dengan layanan kesehatan dan beberapa peralatan kesehatan untuk yang dikenakan pada tubuh Lansia, dan termasuk system monitor kesehatan. Pada sistem yang sudah dirancang secara baik dan terintegrasi antara teknologi dan layanan sosial, maka selain alat monitor kesehatan, AAL, emergency rescue, hal-hal lain yang terdapat di dalamnya adalah layanan perawatan, layanan dokter, interaksi social dengan keluarga dan kerabat, lihat gambar no. 4 (Alosaimi, et al., 2021). Semua ini dimaksudkan agar Lansia dapat hidup secara mandiri, produktif dan sejahtera. 


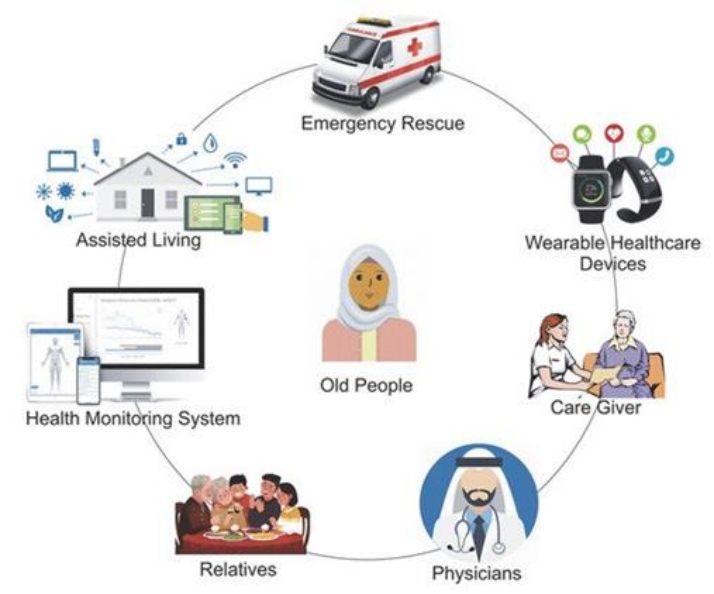

Gambar 4 Representasi Grafis dari sebuah sistem Ambient Assisted Living (AAL) Sumber: (Alosaimi, et al., 2021)

\section{Pendekatan riset dan penciptaan yang dapat diterapkan}

Salah satu pendekatan yang banyak dipakai adalah Universal design (Beer, Oleńska, Podobas, \& Zbieć, 2017) (van der Cammen, Wang, \& Albayrak, 2019) (Izani, Alkhalidi, \& Razak, 2019). Pada bagian berikut akan dibicarakan secara lebih detail pendekatan universal design yang sangat cocok untuk meneliti maupun merancang lingkungan dan fasilitas untuk lansia. Universal design diperkenalkan pertama oleh seorang arsitek yaitu Ronald L. Mace, pada tahun 1970-an, dan konsep ini menjadi kuat dan formal pada tahun 1989, dengan pembentukan pusat riset dan penciptaan yang disebut dengan nama The Center for Universal design .

Universal design menekankan bahwa dalam pemakaian produk, ruang dan atau lingkungan hidup tidak boleh ada diskriminasi dan ketidak setaraan antara mereka yang mempunyai perbedaan kemampuan, termasuk di sini untuk orang berkebutuhan khusus (difabel) dan orang yang sudah tua. Dengan kata lain tujuan dari penerapan prinsip universal design adalah untuk mendapatkan solusi yang lebih baik dalam rangka melayani kebutuhan pemakai dan untuk memastikan kemampuannya memuaskan kebutuhan mereka, tanpa memandang kecocokan fisik, ketrampilan dan pengetahuannya. Sejak tahun 1990-an universal design berkembang di seluruh dunia, di Eropa konsep ini lebih dikenal sebagai inclusive design.

Pendekatan universal design dan inclusive design keduanya mempunyai tujuan membuat produk, layanan atau lingkungan yang lebih inklusi, artinya cakupan manfaat desainnya dapat dipakai secara lebih mudah oleh berbagai jenis katagori pemakai. Universal design biasanya lebih fokus pada suatu solusi yang dapat dipakai oleh sebanyak mungkin orang, sedangkan inclusive design lebih perhatian pada merancang untuk kelompok orang tertentu atau fungsi yang spesifik kemudian hal ini diperlebar ke yang lain (orang/fungsi).

Bersumber dari para ahli di the Centre for Universal design, North Carolina State University, Liu dan Lederer (Liu \& Lederer, 2009) menuliskan tujuh prinsip universal design yang perlu diingat dan dipegang yaitu;

1. Pemakaian yang sama, diasumsikan bahwa desain akan dipakai oleh orang-orang dengan potensi kemampuan yang berbeda.

2. Fleksibilitas dalam penggunaan, sejauh yang dimungkinkan, desain harus memperhitungkan prefernsi dari kelompok pemakai yang berbeda.

3. Sederhana dan intuitif, pemakaian produk ini harus tidak memberikan kesulitankesulitan. Prinsip kemudahan dalam pemakaian tidak pandang pengalaman dan ketrampilan pemakai.

4. Informasi yang mudah dipahami, memastikan aliran informasi kepada pemakai, tanpa pandang kemampuan perseptifnya. 
5. Toleransi kepada kesalahan, meminimalkan akibat kecelakaan dan kegiatan abnormal, pemberitahuan tentang adanya error/kesalahan, keamanan dalam hal terjadi kekeliruan.

6. Upaya fisik yang rendah, mengurangi usaha fisik yang dibutuhkan untuk menggunakan desain ini, seperti mengurangi kegiatan repetisi.

7. Ukuran dan ruang untuk pendekatan dan penggunaan, diasumsikan bahwa produk desainnya mempunyai ukuran yang sesuai/ pas, dan ruang yang dibutuhkan mencukupi agar dapat menangani/ megoperasikannya - sesuai postur dan mobilitas pemakai (Liu \& Lederer, 2009).

Untuk mengaplikasikan prinsip-prinsip tersebut dalam perancangan untuk Lansia masih perlu ditambahi dengan beberapa catatan tambahan pada masing-masing item, hal tersebut terkait dengan usability atau keterpakaiannya oleh user/ pemakai, lihat lebih jauh pada Liu dan Lederer (Liu \& Lederer, 2009).

Terakhir riset-riset terbaru di terkait dengan Lansia menunjukkan bahwa selain mengaplikasikan pendekatan universal design ini mereka mendasarkan proses perancangan mereka pada user centered design. Yaitu proses desain yang berfokus pada kebutuhan pengguna. Produk, jasa dan lingkungan yang dirancang dioptimalkan untuk pemakai serta ditekankan pada bagaimana kebutuhan atau keinginan pemakai terhadap penggunaan produk, jasa atau lingkungan tersebut (Sanders \& Stappers, Co-creation and the New Landscapes of Design, 2008). Desain dirancang dengan adaptasi terhadap behavior atau perilaku pengguna dalam menggunakan objek sehingga dalam pemakainnya tidak memaksa pengguna untuk mengubah perilakunya. Prinsip ini dimaksudkan agar produk yang dikembangkan dapat bermanfaat secara optimal dan mudah dalam pemakaian.

Membaca pada peta lanskap dan penjelasan yang pernah dipropos oleh Sanders (Sanders, Design Research in 2006, 2006), dan Sanders dan Stappers (Sanders \& Stappers, Co-creation and the New Landscapes of Design, 2008) dalam kelompok user centered design dipahami sebagai riset dan penciptaan yang diprakarsai oleh para ahli dan desainer, sedangkan pemakai dalam hal ini menjadi objek saja. Dalam kelompok user centered design ini ada beberapa pendekatan yaitu dari yang terbesar ergonomic/ human factors, usability design, applied ethnography, contextual inquiry, dan lead user innovation.

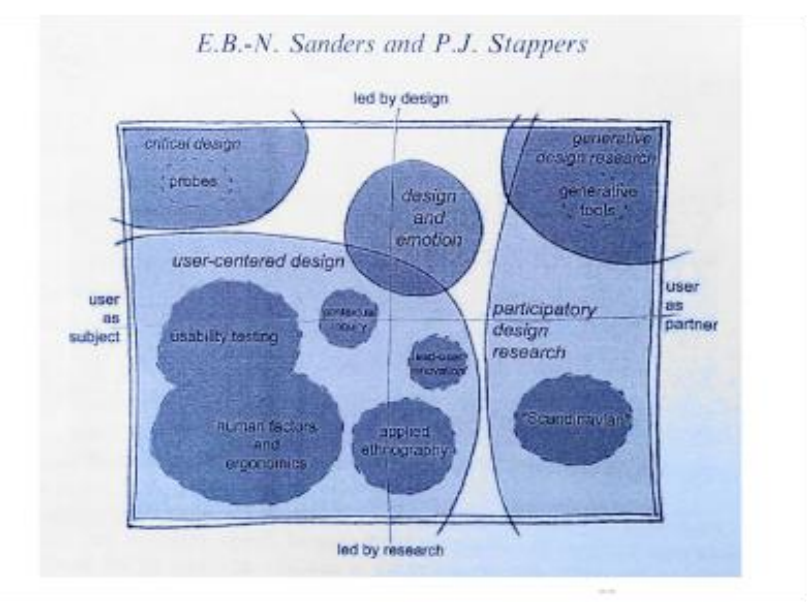

Gambar 5 Lanskap human-centered design research yang dipraktikan pada penelitian dan penciptaan produk dan layanan.

Sumber : (Sanders \& Stappers, Co-creation and the New Landscapes of Design, 2008)

Secara ringkas masing-masing dapat dijelaskan sebagai berikut, ergonomi sudah cukup jelas memang sangat dibutuhkan karena adanya perubahan fisik pada Lansia. Usability design sebagai metode dapat dan perlu dilakukan untuk mengujicoba unjuk kerja peralatan atau ruang bagi Lansia tersebut. Applied ethnography juga dapat dipakai sebagai metode pendekatan desain, karena latar 
belakang budaya Lansia jelas berpengaruh pada desain yang dipergunakannya. Sementara itu pendekatan contextual inquiry merupakan metode yang biasa dipakai dalam pengembangan software IT, penerapan metode ini dengan sesi diskusi satu satu, desainer dengan pemakai, untuk mendapatkan tanggapan langsung terhadap unjuk kerja peralatan dan penerimaannya terhadap peralatan tersebut ketika alat tersebut sedang digunakan. Dan yang terakhir lead user innovation adalah metode yang menekankan bahwa inovasi berasal dari pemakai bukan dari perusahaan pembuat alat tersebut. Dikembangkan oleh von Hippel pada tahun 1988, dikatakan bahwa pada metode ini memang tidak semua konsumen dapat menjadi nara sumber untuk inovasi hanya beberapa konsumen yang memang punya keahlian dalam bidang tersebut yang dapat menjadi partner untuk melahirkan inovasi desain.

\section{Simpulan}

Dari pembahasan tersebut di atas dapat ditarik beberapa kesimpulan, yaitu:

- Bahwa di masa depan jumlah penduduk Lansia di Indonesia akan terus bertambah, sejalan dengan pertumbuhan kesejahteraan masyarakat dan perbaikan jaminan kesehatan.

- Para Lansia mempunyai kebutuhan desain yang berubah karena hadirnya beberapa perubahan yaitu fisik, pencerapan indera, dan kognisi, dalam hal ini desain dapat serta perlu memberi kontribusi dalam menyediakan produk, lingkungan, dan layanan yang sesuai dengan kebutuhan baru para Lansia.

- Untuk perancangan produk, lingkungan, dan layanan yang ramah Lansia disarankan untuk memakai pendekatan desain yang inklusif atau universal design serta proses perancangan yang berpusat pada pemakai (user centered design).

- Dengan desain yang baik (ramah Lansia) akan dapat membantu para Lansia hidup lebih mandiri dalam kesehariannya.

- Penelitian dan perancangan produk, layanan dan lingkungan yang ramah Lansia agar diintensifkan terutama oleh lembaga-lembaga milik pemerintah dan perguruan tinggi, dengan hadirnya riset dan desain baru yang inovatif, baik produk, layanan dan lingkungan yang ramah Lansia, akan dapat mengurangi beban masyarakat dalam merawat dan mengelola kehidupan para Lansia.

- Penelitian dan desain untuk para Lansia agar dapat hidup mandiri dalam kesehariannya perlu dipopulerkan sejak sekarang kepada para mahasiswa sekolah desain dan para desainer muda, agar pada masanya nanti mereka dapat berpartisipasi menciptakan lebih banyak desain yang ramah Lansia.

\section{Daftar Pustaka}

Alosaimi, W., Ansari, M., Alharbi, A., Alyami, H., Seh, A. H., Pandey, A. K., . . Khan, R. A. (2021). Evaluating the Impact of Different Symmetrical Models of Ambient Assisted Living Systems. Symmetry, 13(3). https://doi.org/10.3390/sym13030450

Beer, P., Oleńska, S., Podobas, I., \& Zbieć, M. (2017). Design for AAL Integrated Furniture for the Care and Support of Elderly and Disabled People. DRVNA INDUSTRIJA, 185-193. DOI:10.5552/drind.2017.1642

Chiara, J. D., Panero, J., \& Zelnik, M. (1992). Time-Saver Standards for Interior Design and Space Planning. New York: McGraw-Hill, Inc.

Ching, F. D. (1987). Interior Design Illustrated. New York: Van Nostrand Rheinhold, Inc. 
Costa, R., Carneiro, D., Novais, P., Lima, L., Machado, J., Marques, A., \& Neves, J. (2008). Ambient Assisted Living. Advances in Soft Computing , 86-94. DOI: 10.1007/978-3-54085867-6_10

Fiorini, L., D’Onofrio, G., Limosani, R., Sancarlo, D., Greco, A., Giuliani, F., . . Cavallo, F. (2017). ACCRA Project: Agile Co-Creation for Robots and Aging. Ambient Assisted Living, 133-150.

Flint, B., \& Tadi, P. (2020, Desember 2). Physiology, Aging. Diambil kembali dari NCBI: https://www.ncbi.nlm.nih.gov/books/NBK556106/

Izani, M., Alkhalidi, A., \& Razak, A. (2019). Concept Awareness of Universal Design in Interior Design Program in the U.A.E. Pertanika Journal of Social Sciences \& Humanities, 21092120.

Kilmer, R., \& Kilmer, W. O. (2014). Designing Interior, 2nd ed. Hoboken, New Jersey: John Wiley \& Sons, Inc.

Liu, L., \& Lederer, R. (2009). Aging and Ergonomics. Dalam S. Kumar, Ergonomics for Rehabilitation Professionals (hal. 103-131). Boca Raton: CRC Press.

Monekosso, D., Florez-Revuelta, F., \& Remagnino, P. (2015). Ambient Assisted Living. IEEE Intelligent Systems, 2-6.

Sanders, E. B.-N. (2006). Design Research in 2006. Design Research Quarterly, 3-8. Diambil kembali dari Design Research Society.

Sanders, E. B.-N., \& Stappers, P. J. (2008). Co-creation and the New Landscapes of Design. CoDesign, 5-18.

van der Cammen, T. J., Wang, G., \& Albayrak, A. (2019). van der Cammen, Tischa J. M. , Wang, G., Albayrak, A., 2019, Where ergonomics meets geriatrics: the connection between comprehensive geriatric assessment and design for ageing, European Geriatric Medicine. European Geriatric Medicine, 333-335. https://doi.org/10.1007/s41999-019-00171-7

Statistik Penduduk Lanjut Usia 2020, Katalog: 4104001, Badan Pusat Statistik Indonesia.

https://www.eithealth.eu/-/sparking-ideas-for-healthcare-solutions-in-areas-of-bringing-carehome-and-real-world-data- $/$.

www.gov.scot/publications/fairer-scotland-older-people-framework-action 